\title{
AVALIAÇÃO DA METODOLOGIA FMEA COMO FERRAMENTA PARA REDUZIR IMPACTOS AMBIENTAIS NO PROCESSO MANUTENÇÃO INDUSTRIAL
}

\section{EVALUATION OF FMEA METHODOLOGY AS A TOOL TO REDUCE ENVIRONMENTAL IMPACTS IN THE INDUSTRIAL MAINTENANCE PROCESS}

\author{
Fabio André Brand ${ }^{1}$, Carla Dalmolin², Xisto Lucas Travassos Jr. ${ }^{3}$, Wagner Mauricio \\ Pachekoski $^{4}$ \\ ${ }^{1}$ Faculdade de Tecnologia SENAI Cimatec.fabiobrand@hotmail.com \\ 2 Faculdade de Tecnologia SENAI Cimatec.carla.dalmolin@gmail.com \\ ${ }^{3}$ Faculdade de Tecnologia SENAI Cimatec.lucas.travassos@fieb.org.br \\ ${ }^{4}$ Faculdade de Tecnologia SENAI Cimatec.wagner.pachekoski@fieb.org.br
}

http://dx.doi.org/10.5902/223611707447

\section{RESUMO}

Nos últimos anos, eventos climáticos extremos tornaram a questão do desenvolvimento sustentável um assunto de discussão freqüente e pauta central de inúmeros encontros globais. A preocupação com a garantia de perpetuação da vida na Terra deve ser de todos, mas nas empresas as exigências são maiores, já que as indústrias são responsáveis pela maior parte do consumo dos recursos naturais. Comprometer-se com o meio ambiente é, assim, uma obrigação de todas as empresas que queiram sobreviver na economia globalizada. Para enfrentar estes novos desafios de produzir mais com menos, as empresas devem adotar metodologias de gestão que possam contribuir para a sustentabilidade de seus processos. Neste estudo analítico, elaboramos uma proposta de modificação da metodologia "FMEA - Failure Mode and Effects Analysis" - Análise do Modo e Efeitos de Falha - para contemplar conceitos de proteção ao meio ambiente para sua aplicação no processo manutenção industrial, com foco em uma produção mais limpa, principalmente impedindo a quebra de máquinas que possam gerar impactos ambientais de qualquer espécie ou então minimizar os efeitos no meio ambiente quando da ocorrência de falhas. Com isso poderemos avaliar o processo manutenção industrial, também sob a ótica de proteção ao meio ambiente, utilizando a metodologia FMEA adaptada a esta nova realidade de desenvolvimento sustentável.

Palavras-chave: Desenvolvimento Sustentável, Manutenção Industrial, FMEA.

\begin{abstract}
In recent years, extreme weather events brought the issue of sustainable development as the main subject of frequent discussion and central agenda of numerous global meetings. The concern with ensuring the perpetuation of life on earth is everyone's responsibility, but in companies this
\end{abstract}


BRAND et al., v(10), no 10, p. 2081-2090, JAN-ABR, 2013.

Rev. Elet. em Gestão, Educação e Tecnologia Ambiental (e-ISSN: 2236-1170)

responsibility is much higher, since the industries are responsible for most of the consumption of natural resources. Commit to the environment is therefore an obligation for all companies that want to survive in the globalized economy.To meet these new challenges of producing more with less, companies must adopt management methods that may contribute to the sustainability of its processes. This study will analyze the "FMEA - Analysis of Failure Mode and Effects - considering the inclusion of the sustainability concept in this methodology, focusing on cleaner production, mainly by preventing the breakdown of machinery which may generate environmental impacts of any kind. With this process we can assess the maintenance industry, also from the viewpoint of environmental protection, using the FMEA methodology adapted to this new reality of sustainable development.

Keywords: Sustainable Development, Maintenance Management, FMEA.

\section{INTRODUÇÃO}

O ambiente empresarial enfrenta modificações constantes na conjuntura e faz da adaptação de suas organizações frente a esses desafios o fator primordial de sobrevivência e também do sucesso. Significa dizer que a dinamicidade do mercado e a concorrência acirrada colocam em risco as empresas que não revisarem seus paradigmas gerenciais constantemente.

A percepção da dimensão ambiental, agregada às práticas administrativas e empresariais, transformou as organizações. Até a década de 80 , a proteção ambiental era tida como uma atividade marginal, custosa, indesejável e que deveria ser evitada para não comprometer o desempenho competitivo. A partir daí, os gastos com proteção ambiental passaram a ser vistos não mais como despesas, mas sim como investimentos para o futuro, e contraditoriamente, para a manutenção da competitividade das empresas.

Para o processo Manutenção industrial não é diferente. Segundo a ABRAMAN - Associação Brasileira de Manutenção:

[...] precisamos seguir os mesmos requisitos exigidos da produção: desenvolvimento econômico, preservação ambiental e responsabilidade social. Diretamente ligada à redução de custos, a Manutenção firmou-se como elemento essencial à garantia de qualidade e da sustentabilidade dos processos produtivos [...]. (Revista ABRAMAN. São Paulo: n.126, Set. 2010)

É nesta linha de raciocínio que este trabalho de pesquisa está centrado, buscando relacionar a gestão tradicional da Manutenção, que utiliza a metodologia FMEA focada nas falhas funcionais puras (paradas de produção), com as novas tendências, que levam em consideração as questões ambientais das falhas dos equipamentos. Estas novas tendências têm convergido na busca de um único objetivo, que é tornar a empresa cada vez mais lucrativa - como é esperado dela pelos seus acionistas e funcionários -, e sustentável, que provavelmente é o que a sociedade ou nossos filhos e netos esperam dela. 
BRAND et al., v(10), no 10, p. 2081-2090, JAN-ABR, 2013.

Rev. Elet. em Gestão, Educação e Tecnologia Ambiental (e-ISSN: 2236-1170)

\section{METODOLOGIA}

Este estudo caracteriza-se como analítico, uma vez que seu objetivo é apresentar a utilização da metodologia FMEA como uma ferramenta de identificação e/ou a antecipação de falhas do processo manutenção que possam gerar impactos ambientais. Avaliou-se a metodologia "FMEA - Failure Mode and Effect Analysis", que pode ser descrito como "[...] um método sistemático para identificar e prevenir problemas em processos e produtos antes que eles ocorram, sempre focando na prevenção de defeitos, melhoria da segurança e incremento da satisfação dos clientes [...]." (MIKULAK e McDERMONTT, 2009, p.2). Esta metodologia nasceu na indústria aeronáutica, em meados dos anos 60, direcionada basicamente para questões de segurança, ou seja, para evitar acidentes e incidentes, que no caso dos equipamentos aeronáuticos, causavam grandes perdas. Com o passar dos anos, as empresas foram adaptando a metodologia FMEA para ser usada como ferramenta na melhoria da qualidade dos produtos, para análise dos processos produtivos e para análise do processo manutenção, sempre buscando o aumento de sua confiabilidade. Para PALADY (1997), o FMEA tradicional pode ser aplicado nas seguintes situações:

- Para diminuir a probabilidade da ocorrência de falhas em projetos de novos produtos ou processos;

- Para diminuir a probabilidade de falhas potenciais (ou seja, que ainda não tenham ocorrido) em produtos/processos já em operação;

- $\quad$ Para aumentar a confiabilidade de produtos ou processos já em operação por meio da análise das falhas que já ocorreram;

- Para diminuir os riscos de erros e aumentar a qualidade em procedimentos administrativos.

Existem, basicamente, dois tipos de FMEA:

- DFMEA - Design Failure Modes and Effects Analysis: focado nas falhas potenciais em projetos de sistemas, sub-sistemas e componentes;

- PFMEA - Process Failure Modes and Effects Analysis: este por sua vez esta focado nas falhas potenciais durante as diversas etapas de todo tipo de processos (manufatura, montagens, manutenção Etc.);

Os dois tipos de FMEA compartilham do mesmo procedimento e visam os mesmos objetivos. Por possuírem as mesmas características, acabam por exercer influência um no outro.

Neste estudo, usaremos a metodologia PFMEA, que chamaremos somente de FMEA, aplicado no processo manutenção, focado na melhoria da confiabilidade dos equipamentos sob o ponto de vista de preservação do meio ambiente.

O FMEA pode ser aplicado seguindo-se sete passos, expostos no Quadro 1 abaixo: 
BRAND et al., v(10), no 10, p. 2081-2090, JAN-ABR, 2013.

Rev. Elet. em Gestão, Educação e Tecnologia Ambiental (e-ISSN: 2236-1170)

Quadro 1 - Passos para Aplicação do FMEA tradicional

\begin{tabular}{|c|c|}
\hline & $\begin{array}{l}\text { Identificar todos os sistemas, subsistemas e componentes do } \\
\text { processo/equipamentos em análise. }\end{array}$ \\
\hline . & $\begin{array}{l}\text { Listar todas as formas possíveis segundo as quais os componentes } \\
\text { poderiam falhar (os modos de falhas). }\end{array}$ \\
\hline & $\begin{array}{l}\text { Identificar os efeitos possíveis das falhas (tempo parado, insegurança, } \\
\text { necessidade de ajustes e/ou consertos, efeitos para os clientes). }\end{array}$ \\
\hline & Identificar as causas possíveis das falhas para cada modo de falha. \\
\hline . & $\begin{array}{l}\text { Avaliar a probabilidade de falha, a severidade dos efeitos da falha e a } \\
\text { probabilidade de detecção. }\end{array}$ \\
\hline 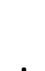 & Identificar o número de prioridade de risco (NPR). \\
\hline . & $\begin{array}{l}\text { Desenvolver e implementar ações para minimizar as falhas } \\
\text { identificadas. }\end{array}$ \\
\hline
\end{tabular}

Fonte: adaptado de SLACK (2002)

Além disso, para o funcionamento e aplicação do FMEA é necessário um prévio planejamento e definição das pessoas que devem fazer parte do grupo/time de trabalho para a sua aplicação. "Recomenda-se para composição deste grupo um número pequeno de pessoas e que tenham domínio do processo, além da definição de um responsável." (TOLEDO e AMARAL, 2006).

A aplicação da FMEA consiste no preenchimento de um formulário, seguindo-se os passos descritos no Quadro 1. Um exemplo de formulário para aplicação do FMEA pode ser observado no Quadro 2 abaixo, adaptado para o processo Manutenção. As respostas aos itens solicitados devem resultar da análise dos integrantes da equipe responsável pela aplicação da ferramenta.

Quadro 2 - Representação do Formulário FMEA para Manutenção

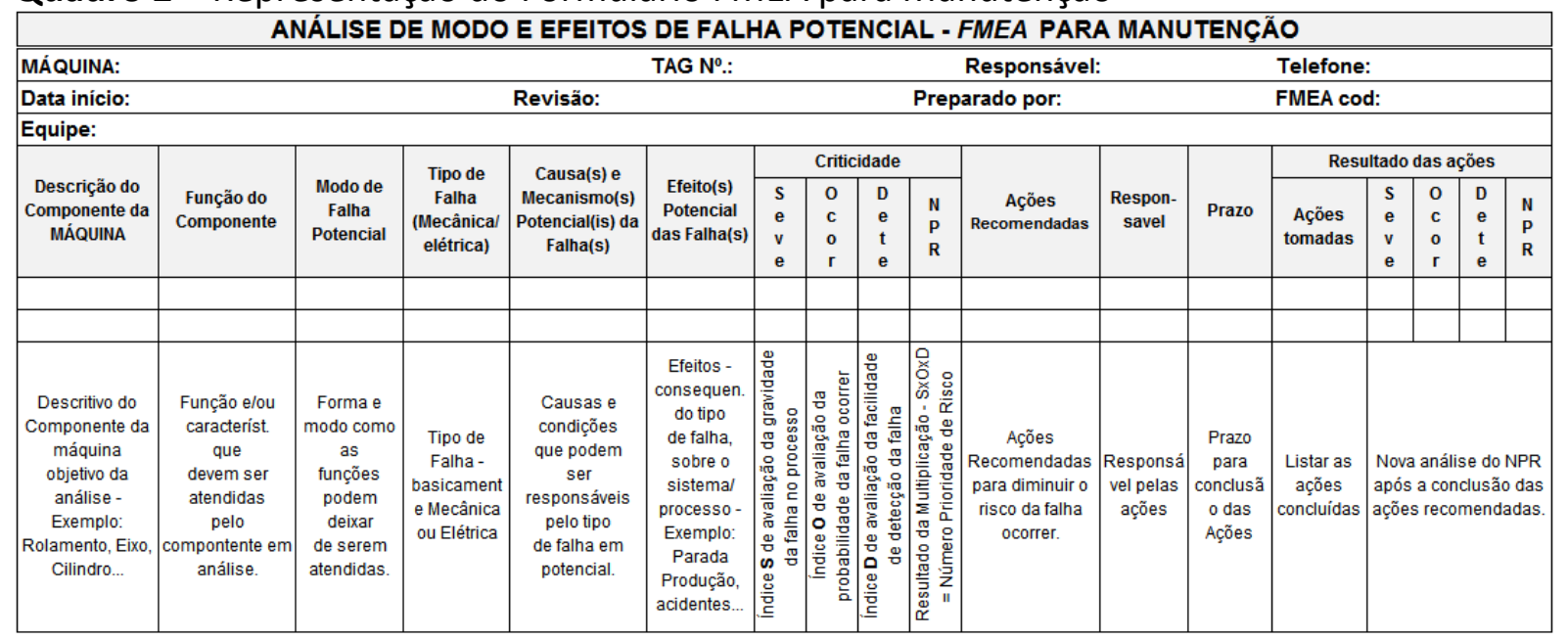


BRAND et al., v(10), no 10, p. 2081-2090, JAN-ABR, 2013.

Rev. Elet. em Gestão, Educação e Tecnologia Ambiental (e-ISSN: 2236-1170)

É importante mencionar também que uma máquina deve ser estratificada em sistemas e subsistemas, conforme esquematizado na Figura 1. Dentro destes deve-se listar todos os seus componentes, que por definição, são as menores partes que compõe a máquina.

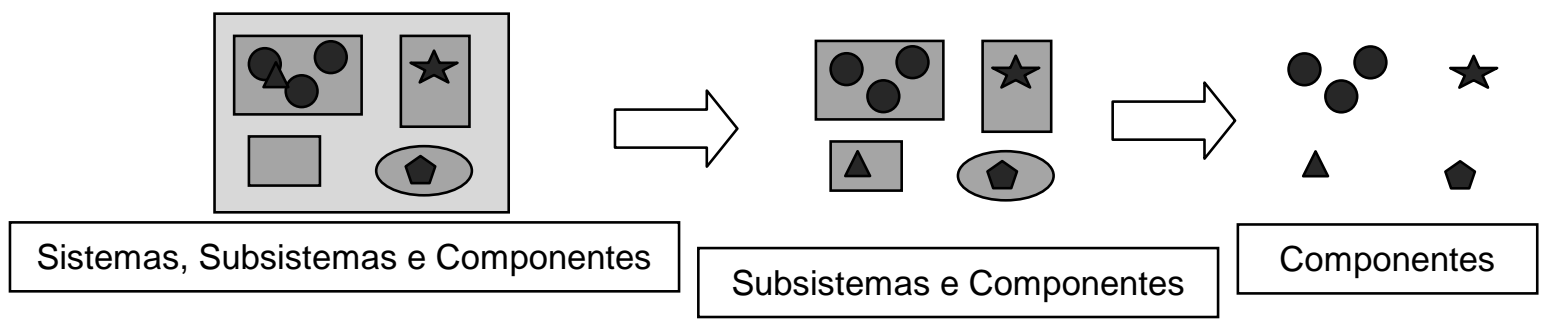

Figura 1. Estratificação de sistemas em subsistemas e componentes.

Observa-se que o preenchimento da FMEA deve seguir alguns critérios e que o grupo de pessoas responsáveis pela execução da ferramenta deve conhecer o processo de desenvolvimento para que as informações inseridas no formulário sejam realmente confiáveis. Além disso, quanto maior o grau de detalhamento, maiores serão as possibilidades de controle e acompanhamento na prevenção das potenciais falhas. Para preenchimento dos itens de severidade, ocorrência e detecção, deve-se observar cuidadosamente qual o índice mais adequado para cada falha e sua respectiva causa, valendo-se da escala definida para cada item. Abaixo relacionados o Quadro 3 com escalas típicas focadas na prevenção de falhas que gerem paradas da máquina, ou seja, perdas de produção, onde o cliente não se resume ao usuário final do produto, mas também ao processo seguinte na linha de produção.

Os tempos de parada de produção podem ser personalizados para cada tipo de empresa, sempre focando nos itens mais críticos no que diz respeito à confiabilidade. Observe também que em nenhum ponto do Quadro 3 abaixo se verifica a questão ambiental do processo em análise, somente aspectos de confiabilidade do processo ou qualidade do produto. 
BRAND et al., v(10), no 10, p. 2081-2090, JAN-ABR, 2013.

Rev. Elet. em Gestão, Educação e Tecnologia Ambiental (e-ISSN: 2236-1170)

Quadro 3 - Representação da escala típica do FMEA tradicional para definição das prioridades

\begin{tabular}{|c|l|l|l|}
\hline Índice & \multicolumn{1}{|c|}{ Severidade } & \multicolumn{1}{|c|}{ Ocorrência } & \multicolumn{1}{|c|}{ Detecção } \\
\hline 1 & $\begin{array}{l}\text { Minima - o cliente mal percebe que a } \\
\text { falha ocorreu / Não ocorre parada de } \\
\text { produção. }\end{array}$ & $\begin{array}{l}\text { Remota - dificilmente } \\
\text { ocorre a causa que leva à } \\
\text { falha }\end{array}$ & $\begin{array}{l}\text { Muito Grande - } \\
\text { Certamente } \\
\text { será detectado }\end{array}$ \\
\hline 2 & $\begin{array}{l}\text { Pequena - ligeira deterioração no } \\
\text { desempenho com leve } \\
\text { descontentamento do cliente / Parada } \\
\text { de Produção menor que 60 min }\end{array}$ & $\begin{array}{l}\text { Pequena - ocorre a causa } \\
\text { da } \\
\text { falha em pequena escala }\end{array}$ & $\begin{array}{l}\text { Grande - Grande } \\
\text { probabilidade de ser } \\
\text { detectado }\end{array}$ \\
\hline 4 & $\begin{array}{l}\text { Moderada - Deterioração significativa } \\
\text { no desempenho de um sistema com } \\
\text { descontentamento do cliente / Parada }\end{array}$ & $\begin{array}{l}\text { Moderada - às vezes } \\
\text { ocorre } \\
\text { a causa que leva à falha }\end{array}$ & $\begin{array}{l}\text { Moderada - } \\
\text { Provavelmente } \\
\text { será detectado }\end{array}$ \\
\hline 7 & $\begin{array}{l}\text { Alta - o sistema deixa de funcionar e } \\
\text { há grande descontentamento do } \\
\text { cliente / Parada de Produção entre } \\
120 \text { min e 720 min. }\end{array}$ & $\begin{array}{l}\text { Alta - ocorre a causa da } \\
\text { falha com certa freqüência }\end{array}$ & $\begin{array}{l}\text { Pequena - } \\
\text { Provavelmente } \\
\text { não será detectado }\end{array}$ \\
\hline 9 & $\begin{array}{l}\text { Muito Alta - idem ao anterior, porém } \\
\text { afeta a segurança (cliente ou } \\
\text { operadores) / Parada de produção } \\
\text { maior que 720 min. }\end{array}$ & $\begin{array}{l}\text { Muito Alta -ocorre a causa } \\
\text { da falha em vários } \\
\text { momentos }\end{array}$ & $\begin{array}{l}\text { Muito Pequena - } \\
\text { Certamente } \\
\text { não será detectado }\end{array}$ \\
\hline
\end{tabular}

Fonte: adaptado de FMEA Reference Guide

\section{RESULTADOS E DISCUSSÃO}

Objetivamos neste estudo a utilização da metodologia FMEA como uma ferramenta de identificação e/ou antecipação de falhas do processo manutenção, falhas estas que possam gerar impactos ambientais. Para tal, precisamos focar na escala de definição de prioridades (Quadro 3), uma vez que a questão de impactos ambientais relacionados as falhas não esta inserida nesta escala.

Analisando a escala típica, observamos que o único índice no qual podemos propor alterações é Severidade, uma vez que os outros dois índices (Ocorrência e Detecção) sofrerão a mesma análise sob a ótica de confiabilidade e de proteção ao meio ambiente. Abaixo descrevemos o quadro 4, onde inserimos no índice severidade algumas diretrizes para classificar a gravidade da falha considerando o impacto que ela cause para o meio ambiente. Importante frisar também que estas diretrizes podem ser customizadas para cada empresa, dependendo do enfoque que se queira dar para a análise FMEA em questão. 
BRAND et al., v(10), no 10, p. 2081-2090, JAN-ABR, 2013.

Rev. Elet. em Gestão, Educação e Tecnologia Ambiental (e-ISSN: 2236-1170)

Quadro 4 - Nova escala de prioridades do FMEA com inserção da questão ambiental

\begin{tabular}{|c|c|c|c|}
\hline Índice & Severidade & Ocorrência & Detecção \\
\hline 1 & $\begin{array}{l}\text { Mínima - o cliente mal percebe que a } \\
\text { falha ocorreu / Não ocorre parada de } \\
\text { produção. } \\
\text { Impacto ambiental dificilmente será } \\
\text { visível, sendo o efeito da falha } \\
\text { muito pequeno para ocasionar um } \\
\text { impacto no meio ambiente. }\end{array}$ & $\begin{array}{l}\text { Remota - dificilmente } \\
\text { ocorre a causa que leva à } \\
\text { falha }\end{array}$ & $\begin{array}{l}\text { Muito Grande - } \\
\text { Certamente } \\
\text { será detectado }\end{array}$ \\
\hline $\begin{array}{l}2 \\
3\end{array}$ & $\begin{array}{l}\text { Pequena - ligeira deterioração no } \\
\text { desempenho com leve } \\
\text { descontentamento do cliente / Parada } \\
\text { de Produção menor que } 60 \text { min } \\
\text { Não-conformidade com a política } \\
\text { ambiental da empresa. Impacto } \\
\text { baixo ou muito baixo sobre o meio } \\
\text { ambiente. }\end{array}$ & $\begin{array}{l}\text { Pequena - ocorre a causa } \\
\text { da falha em pequena } \\
\text { escala }\end{array}$ & $\begin{array}{l}\text { Grande - Grande } \\
\text { probabilidade de ser } \\
\text { detectado }\end{array}$ \\
\hline $\begin{array}{l}4 \\
5 \\
6\end{array}$ & $\begin{array}{l}\text { Moderada - Deterioração significativa } \\
\text { no desempenho de um sistema com } \\
\text { descontentamento do cliente / Parada } \\
\text { de Produção entre que } 60 \text { e } 120 \text { min } \\
\text { Não-conformidade com os } \\
\text { requisitos legais e normativos. } \\
\text { Prejuízo moderado ao meio } \\
\text { ambiente. }\end{array}$ & $\begin{array}{l}\text { Moderada - às vezes } \\
\text { ocorre a causa que leva à } \\
\text { falha }\end{array}$ & $\begin{array}{l}\text { Moderada - } \\
\text { Provavelmente } \\
\text { será detectado }\end{array}$ \\
\hline $\begin{array}{l}7 \\
8\end{array}$ & $\begin{array}{l}\text { Alta - o sistema deixa de funcionar e } \\
\text { há grande descontentamento do } \\
\text { cliente / Parada de Produção entre } \\
120 \text { min e } 720 \text { min. } \\
\text { Sério pre juízo ao meio ambiente, } \\
\text { com contaminação grave do solo, } \\
\text { água ou ar. }\end{array}$ & $\begin{array}{l}\text { Alta - ocorre a causa da } \\
\text { falha com certa freqüência }\end{array}$ & $\begin{array}{l}\text { Pequena - } \\
\text { Provavelmente } \\
\text { não será detectado }\end{array}$ \\
\hline $\begin{array}{c}9 \\
10\end{array}$ & $\begin{array}{l}\text { Muito Alta - idem ao anterior, porém } \\
\text { afeta a segurança (cliente ou } \\
\text { operadores) / Parada de produção } \\
\text { maior que } 720 \text { min. } \\
\text { Grande impacto ambiental, com } \\
\text { prejuízo à reputação da empresa e } \\
\text { sujeito a multa de órgãos } \\
\text { ambientais. }\end{array}$ & $\begin{array}{l}\text { Muito Alta -ocorre a causa } \\
\text { da falha em vários } \\
\text { momentos }\end{array}$ & $\begin{array}{l}\text { Muito Pequena - } \\
\text { Certamente } \\
\text { não será detectado }\end{array}$ \\
\hline
\end{tabular}

Observa-se no quadro 4 acima, que o índice Severidade parte de uma análise do efeito do risco, não somente sob o ponto de vista de confiabilidade e qualidade, mas também sob a ótica de impactos ambientais. Desta forma, pode-se avaliar cada modo de falha considerando todos os http://cascavel.ufsm.br/revistas/ojs-2.2.2/index.php/reget 
BRAND et al., v(10), no 10, p. 2081-2090, JAN-ABR, 2013.

Rev. Elet. em Gestão, Educação e Tecnologia Ambiental (e-ISSN: 2236-1170)

seus possíveis impactos ambientais, o que garante a inserção da preocupação com o meio ambiente no processo manutenção industrial.

Para melhor elucidar o efeito das alterações propostas na escala de prioridades do FMEA usado no processo manutenção industrial, faremos uma simulação aplicando o formulário FMEA para a análise de alguns componentes de um Sistema Hidráulico, primeiramente usando a escala típica de prioridades do Quadro 3 e após usaremos a nova escala de prioridades definida no Quadro 4.

Quadro 5 - Formulário FMEA com escala típica de priorização aplicado a Sistema Hidráulico

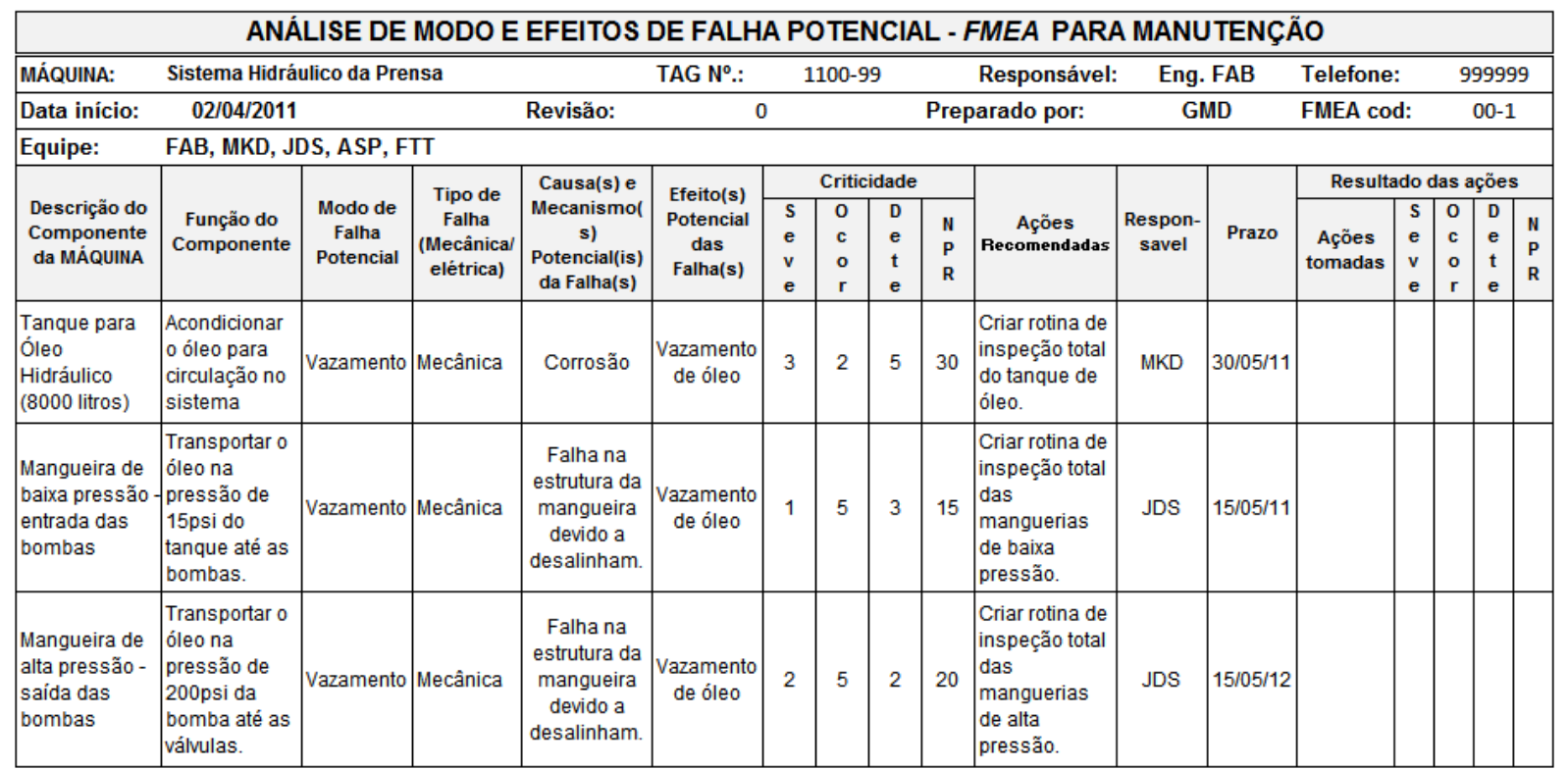

Observa-se no quadro acima, que os valores atribuídos para a severidade de cada falha descrita são baixos, pois se considera nesta análise somente o impacto na confiabilidade do sistema, ou seja, paradas de produção, que no caso de falhas dos componentes descritos, seriam relativamente pequenas, uma vez que são componentes de rápida substituição ou reparo.

Usando os mesmos componentes do sistema hidráulico em questão, aplicaremos o formulário FMEA utilizando a nova escala de priorização proposta, com análise dos aspectos ambientais de cada falha. Poderemos então comparar os resultados obtidos quanto à priorização das ações a serem tomadas para mitigar falhas potenciais e evitar impactos ambientais. Importante mencionar também que a participação de especialistas na área ambiental no time de aplicação do FMEA contribui muito para que todos os aspectos e impactos ambientais sejam contemplados na análise.

Abaixo, apresentamos o Quadro 6, onde destacamos as alterações obtidas após a aplicação da nova escala de priorização. Podemos verificar que os valores da severidade (coluna grifada) foram significativamente aumentados quando comparados ao do quadro 5, quando levamos em consideração os efeitos de cada falha no tocante a impactos ambientais. Com isso, o NPR Número Prioridade Risco também sofreu um aumento médio de $65 \%$ fazendo que as falhas 
BRAND et al., v(10), no 10, p. 2081-2090, JAN-ABR, 2013.

Rev. Elet. em Gestão, Educação e Tecnologia Ambiental (e-ISSN: 2236-1170)

potenciais relacionadas para cada componente sofram uma análise mais criteriosa para definição de ações que possam minimizar possíveis impactos ambientais ou mesmo evitar que estas falhas possam ocorrer. Na coluna de ações do quadro 6 podemos observar alguns exemplos de ações (listadas em destaque) que possuem um foco na minimização de impactos ambientais.

Quadro 6 - Formulário FMEA com nova escala de priorização aplicado a Sistema Hidráulico

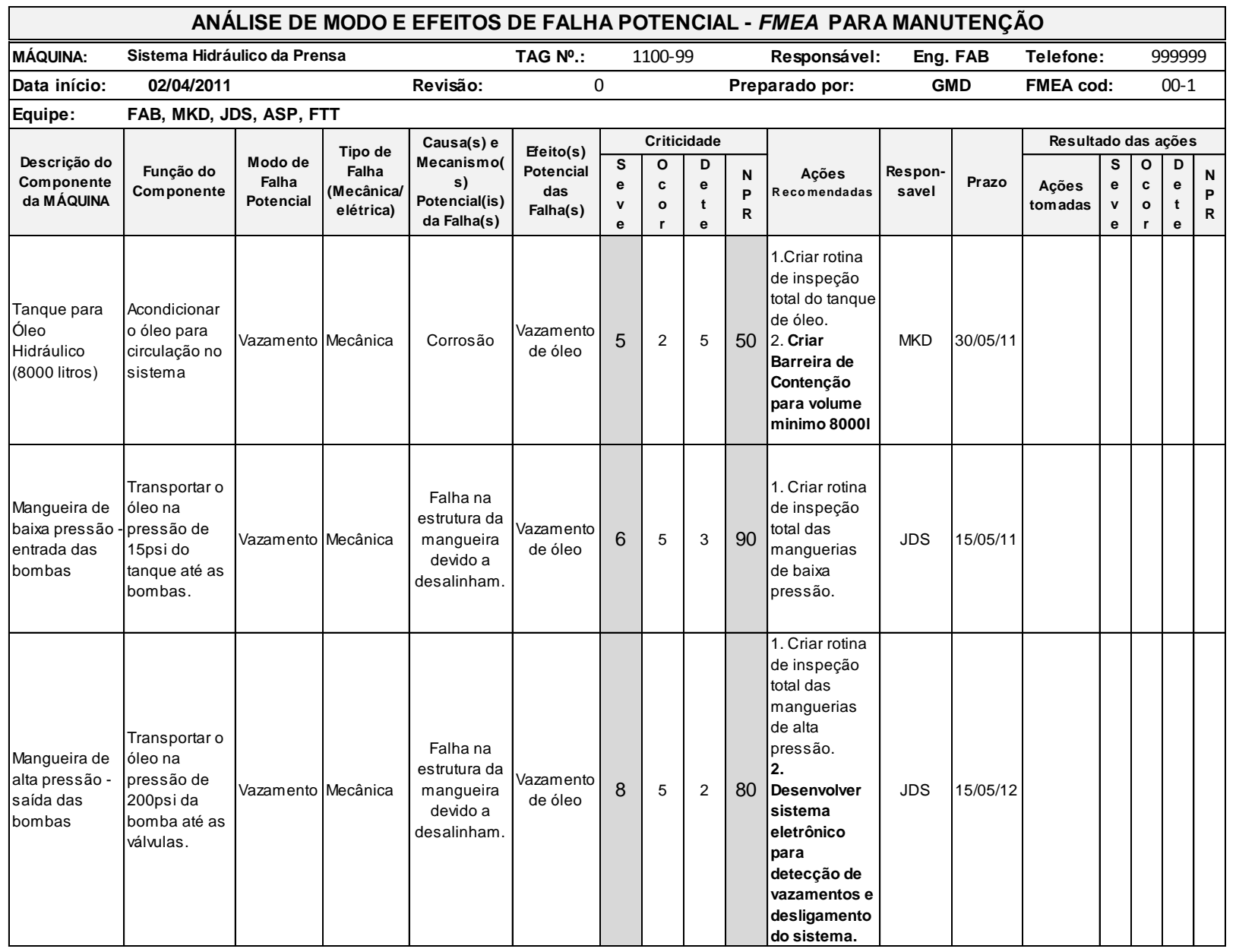

\section{CONCLUSÕES}

O FMEA é um método direcionado para quantificação dos efeitos das possíveis falhas, permitindo à empresa estabelecer prioridades para agir. A utilização do FMEA, aplicado ao processo ao processo manutenção industrial para análise dos riscos ambientais constitui um método simples para avaliar possíveis impactos ambientais segundo uma escala de severidade que pode ser customizada, permitindo assim o estabelecimento direto de medidas preventivas ou corretivas para minimizar ou evitar a ocorrência de danos ao meio ambiente. 
BRAND et al., v(10), no 10, p. 2081-2090, JAN-ABR, 2013.

Rev. Elet. em Gestão, Educação e Tecnologia Ambiental (e-ISSN: 2236-1170)

Em relação às análises apresentadas, é interessante observar que no primeiro caso (Quadro 5), que considera somente aspectos de confiabilidade do sistema, os valores obtidos para o NPR foram relativamente baixos, fazendo com que estas potenciais falhas que poderiam causar impactos ao meio ambiente muitas vezes nem sejam consideradas em um plano de ação específico. Já no segundo caso (Quadro 6), onde se usa a nova escala proposta, verifica-se que os valores de NPR são significativamente maiores (65\%), fazendo com que as causas e efeitos em análise sejam efetivamente considerados em um plano de ação específico para mitigação de possíveis impactos ambientais.

Dentre algumas vantagens observadas da utilização do FMEA com foco na redução de impactos ambientais do processo manutenção industrial pode-se citar:

- a identificação dos modos/causas de falhas potenciais relacionadas ao meio ambiente;

- a identificação das variáveis que deverão ser controladas para redução da ocorrência ou melhoria da eficácia da detecção das falhas;

- a classificação dos modos de falhas potenciais, estabelecendo assim um sistema de padronização para a priorização das ações corretivas/preventivas;

- a aprendizagem relacionada a uma manutenção ligada ao desenvolvimento sustentável.

Assim, verificamos que o FMEA pode ser uma ferramenta poderosa que toda e qualquer empresa pode usar na busca de um processo de manutenção mais eficiente e eficaz, com menos falhas e impactos ao meio ambiente. É fundamental também que na avaliação de riscos ambientais do processo manutenção haja sempre uma retroalimentação do FMEA a partir de experiências acumuladas. $O$ que exige, por parte das empresas, uma rotina de aprimoramento contínuo, que é a base para um sistema de gestão bem sucedido em todos os processos de uma empresa.

\section{REFERÊNCIAS}

ABRAMAN, editorial. Revista da Associação Brasileira de Manutenção, São Paulo: n.126, Set, 2010, p.06. FMEA, Reference Guide. Modes and Effects Analysis (FMEA). International Electrotechnical Commission.

Geneva.

MCDERMOTT, R. E., MIKULAK, R, J,. The Basics of FMEA, Productivity Inc, Portland, 1996.

NOGUEIRA, M.A., FMEA: implantação e resultados na manutenção preventiva em máquina de abatedouro de frangos. São Carlos: UFSCAR, 1998. 152 p. Dissertação (Mestrado em Engenharia de Produção) - Departamento de Engenharia de Produção.

PALADY, P. FMEA: Análise dos modos de falha e efeitos. São Paulo: IMAM, 1997. 270 p.

SLACK, N.; CHAMBERS, S.; HARRISON, A. et. al. 1996. Administração da produção. São Paulo, Atlas, 747 p.

TOLEDO, J.C. e AMARAL, D.C. FMEA: Análise do Tipo e Efeito de Falha. Disponível em

<http://www.gepeq.dep.ufscar.br/arquivos/FMEA-APOSTILA.pdf>, acesso em: mar. 2011. 